\title{
A comparative analysis of promethee, ahp and topsis aiding in financial analysis of firm performance
}

\author{
Aditi Sharma ${ }^{1}$, Gurjeet Kaur ${ }^{2}$, Jatin Bansal ${ }^{3}$ \\ ${ }^{1}$ Bachelor of Business Administration (Financial Investment Analysis), \\ Shaheed Sukhdev College of Business Studies, India \\ ${ }^{2}$ Associate Professor, Department of management studies, \\ Shaheed Sukhdev College of Business Studies, India \\ ${ }^{3}$ Bachelor of Business Administration (Financial Investment Analysis), \\ Shaheed Sukhdev College of Business Studies, India \\ 1aditi.16301@sscbs.du.ac.in, ${ }^{2}$ gurjeetkaur@sscbs.du.ac.in, ${ }^{3} j a t i n .16322 @ s s c b s . d u . a c . i n$,
}

\begin{abstract}
Multi-criteria decision making methods are extensively used in the decision making problems. Decision making is the activity of a person that helps obtain responses to the questions posed by a stakeholder in a decision process. This study compares the financial performance of seven companies in the banking sector listed on the National Stock Exchange (NSE) for years from 2014 to 2017. The PROMETHEE, AHP and TOPSIS methods are used independently to evaluate the financial performance and to decide on the best performing firm for the four year period. The evaluated ranks are then compared with the actual ranks (based on investments) using Spearman's rank correlation. The calculation of financial performance measures is based on four main criteria and nine sub-criteria. Using the following methods, our study suggests that Punjab National Bank (PNB) has the best financial performance as compared to other companies.
\end{abstract}

\section{InTRODUCTION}

$\mathrm{D}$ ECISION-making is an integral part of modern management. Decision making process is continuous and indispensable component of managing any organization or business activities. Decisions are made to sustain all activities and organizational functioning. Trewatha and Newport define the process of decision making as," Decision-making involves the selection of a course of action from among two or more possible alternatives in order to arrive at a solution for a given problem."

Decision -making is considered to be a demanding process due to its subjective nature leading decision-makers to make a choice under various risks and uncertainty. The measurement and the evaluation of the firm performance have gained tremendous importance in the past few years. Thus, it has become essential for the firms to keep a record of their financial performance. Since the financial performance of a firm is analysed using the actual data under concrete mathematical operations, these performance measures provide an insight into the severity of the problems and the precautions to be taken for the same. Since the decisionmakers often have to decide based on multiple criteria under a given situation, multiple-criteria decision making analysis is often used to provide solutions under multiple and incomparable set of data. Our paper aims to use PROMETHEE, AHP and TOPSIS methods to deduce the rankings of the companies based on their financial performance under certain criteria. We also aim to compare these results with the actual rankings of the companies (based on the investments made in them), to deduce which method among the three returns the results closest to the actual scenario. For our study, we use the data on the performance of seven companies of the banking-sector industry, listed on the National Stock Exchange (NSE).

\section{Literature Review}

The decision-making is extensively used in every day. According to H. Koontz and H.Weihrich [3] the decision is defined as choice of the most suitable alternative with respect to the predefined criteria, while T. Hunjak defines it as collection of activities from the problem definition to the alternative selection. The PROMETHEE method helps the decision makers to find an alternative that best suits their conditions. The Analytic Hierarchy Process (AHP) is a structured technique for dealing with complex decisions. It was developed by Thomas L. Saaty in the 1970s. The Technique for Order of Preference by Similarity to Ideal Solution (TOPSIS) is a multi-criteria decision analysis method, which was originally developed by Hwang and Yoon in 1981 with further developments by Yoon in 1987, and Hwang, Lai and Liu in 1993.

Kazan and Ciftci (2013) explain that the AHP method allows researchers to decompose decision making problems into their fundamental components. Albadvi and Chaharsooghi (2007); Herngren et al. (2006); investigates the use of the AHP method in traffic planning. They suggest that an application of the AHP method is one of the possible methodologies which could be implied for the choice of technology in traffic planning. Similar to our study, there is an increasing literature investigating decision making problems using a hybrid structure (Bilsel et al. (2006); Dagdeviren (2008); Kazan and Ciftci (2013)). The use of different multi-criteria decision analysis techniques would maximize the benefits for the user who faces complicated multi-criteria decision problems.

\section{Methodology}

\subsection{Scope Of The Study}

We examine the relationship between the financial performance and the investor's preference in terms of investment, among the banking-sector companies operating in India. Our research uses data for companies listed on the National Stock Exchange (NSE) for the years 2014, 2015, 2016 and 2017.

\subsection{Data And Method Of Analysis}

Multi-Criteria Decision Making method requires the use of various mathematical operations. Therefore, at the solution phase, we make use of Microsoft Excel . The abstraction provides an overall analogy of the performance rankings of each firm determined by the weighted ratios. Later, we examine the stage of relationship between 
the performance ranking obtained with the method determined with each ratio and the rankings published by stock exchange. Our research is conducted using 4 main criteria and 9 sub-criteria. The financial ratios are attained from CAPITALINE which is a paid subscription database.

\subsection{FINANCIAL PERFORMANCE INDICATORS}

The financial performance criteria used in our research are listed below:

\section{GROWTH RATIOS}

- Asset turnover: The asset turnover ratio measures the ability of a company to use its assets to efficiently generate sales. The higher the ratio indicates that the company is utilizing all its assets efficiently to generate sales.

- Investment Deposit: The total of all the long term and short term investment made by the bank on other sources like banks, share market, loans and advances divided by the total amount of deposits raised by the bank by various account

- Earning Retention Ratio: The retention ratio is the proportion of earnings kept back in the business as retained earnings. The retention ratio refers to the percentage of net income that is retained to grow the business, rather than being paid out as dividends.

\section{PERFORMANCE RATIOS}

- Return on Net Worth: the amount of net income returned as a percentage of shareholders equity. Return on equity measures a corporation's profitability by revealing how much profit a company generates with the money shareholders have invested.

- Return on Assets: ROA gives an idea as to how efficient management is at using its assets to generate earnings. Calculated by dividing a company's annual earnings by its total assets.

\section{VALUATION RATIOS}

- Price Earnings Ratio: The price to earnings ratio (PE Ratio) is the measure of the share price relative to the annual net income earned by the firm per share.

- Market Cap/Sales Ratio: It is calculated by dividing the company's market cap by the revenue in the most recent year; or, equivalently, divide the per-share stock price by the per-share revenue.

\section{LIQUIDITY RATIOS}

- Current Ratio: The current ratio considers the current total assets of a company (both liquid and illiquid) relative to that company's current total liabilities.

- Quick Ratio: The quick ratio is a measure of how well a company can meet its short-term financial liabilities. Also known as the acid-test ratio, it can be calculated by: (Cash + Marketable Securities + Accounts Receivable) / Current Liabilities.

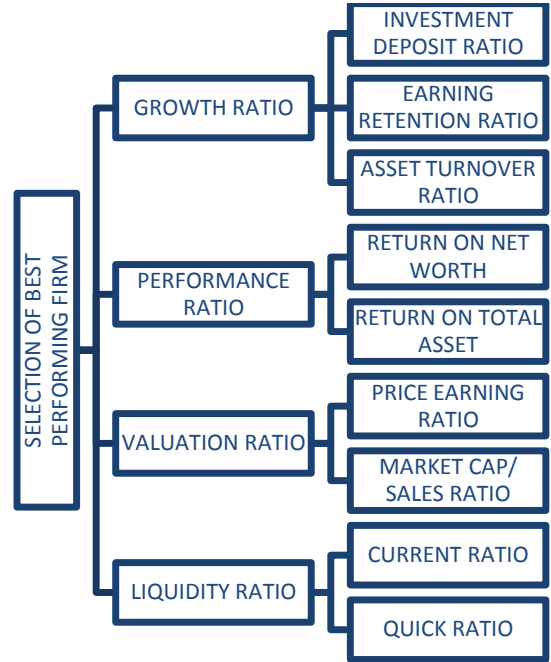

Figure 1: Complete graphical representation of MCDM problem

\begin{tabular}{|l|l|}
\hline Banking Firm's Name & Code \\
\hline State Bank of India & A \\
\hline Axis Bank & B \\
\hline Punjab National Bank & C \\
\hline Canara Bank & D \\
\hline Union Bank of India & E \\
\hline Kotak Mahindra Bank & F \\
\hline ICICI Bank & G \\
\hline
\end{tabular}

Table 1 enlists the name of banking firms trading on National Stock Exchange for the years 2014, 2015, 2016 and 2017.

Multi-criteria decision making (MCDM) methods:

- The Analytic Hierarchy Process

$(A H P)$

$1^{\text {st }}$ Stage: The problem is decomposed into a hierarchy of goal, criteria, sub-criteria and alternatives. $2^{\text {nd }}$ Stage: The pairwise comparisons of various criteria are organized into a square matrix. $3^{\text {rd }}$ Stage: The principal Eigen value and the corresponding normalized right eigenvector of the comparison matrix give the relative importance of the various criteria being compared. $4^{\text {th }}$ Stage: The rating of each alternative is multiplied by the weights of the sub-criteria and aggregated to get local ratings with respect to each criterion.

- The Technique of Order Preference by Similarity to Ideal Solution

(TOPSIS)

$1^{\text {st }}$ Stage: Construct normalized decision matrix. $2^{\text {nd }}$ Stage: Construct the weighted normalized decision matrix. $3^{\text {rd }}$ Stage: Determine the ideal and negative ideal solutions. $4^{\text {th }}$ Stage: Calculate the separation measures for each alternative.

$5^{\text {th }}$ Stage: Calculate the relative closeness to the ideal solution

- $\quad$ The Preference Ranking Organization Method for Enrichment Evaluation (PROMETHEE) The PROMETHEE II Method was developed by J.P.Brans and presented for the first time in 1982 in a conference organized by R. Nadeau and M. Landry at Univesitè Laval, Québec, Canada. The PROMETHEE Method is a pairwise comparison of decision points based on assessment factors. However, unlike other multicriteria decision making methods, it defines a preference function 
consisting of different assessment factors and assigns a relative weight indicating the level of importance of each factor and the internal relations among them.

$1^{\text {st }}$ stage: A data matrix is prepared by scaling the values on the basis of variations in the ratios. $2^{\text {nd }}$ stage: A preference function is defined for each criterion. For the sake of convenience and uniformity, we have used linear preference

function.

$3^{\text {rd }}$ stage: The third stage starts with a comparison (binary) of decision points, i.e. scaled values given to the criteria of each company. Then, the preference function for each criterion is determined.

$4^{\text {th }}$ stage: The positive and negative value for each company in particular criteria is defined. $5^{\text {th }}$ stage: The positive and negative rule set for alternatives. $6^{\text {th }}$ stage: This stage calculates the net priority values of each criterion and orders the companies in rank of preference, thus completing PROMETHEE II.

\section{The Spearman's Rank Correlation}

$1^{\text {st }}$ stage: The actual ranks are extracted from NSE website on the basis of the investments in them. $2^{\text {nd }}$ stage: The formula for the Spearman's rank correlation coefficient is given by the formula:

$$
r_{s}=1-\frac{6 \sum d_{i}^{2}}{n\left(n^{2}-1\right)} .
$$

Where $r_{\mathrm{s}}$ =spearman's rank correlation coefficient $d_{i}=$ difference in the ranks of each observation $\mathrm{n}=$ number of observations $3^{\text {rd }}$ stage: The above formula is used to calculate the correlation between the actual ranks and the ranks obtained by each of the above methods.

\section{ANALysis AND Result}

In this abstraction, the three MCDM models are used which are the PROMETHEE, hybrid structure of the AHP and the TOPSIS and the AHP. The objective of the multi-criteria decision making problem and the estimation of relative weights assigned to each criteria are carried out by the AHP method. The PROMETHEE, the TOPSIS and the AHP methods are used for the final arrangement and ranking.

We assign higher weights to the criteria with the largest coefficient of variance. As a result, a more explicit picture of differences among the companies is anticipated. The relative ratios of coefficient of variance of each criterion are calculated. We then achieve the relative weight of each criterion using the Analytical Hierarchy Process (AHP).

Based on the data:

\begin{tabular}{|l|l|}
\hline RATIOS & WEIGHTS \\
\hline RONW & $\mathbf{0 . 3 4 6 4}$ \\
\hline ROA & $\mathbf{0 . 1 8 2 7}$ \\
\hline Current Ratio & $\mathbf{0 . 1 1 6 0}$ \\
\hline Quick Ratio & $\mathbf{0 . 0 3 5 0}$ \\
\hline Asset Turnover & $\mathbf{0 . 0 2 2 6}$ \\
\hline Investment Deposit & $\mathbf{0 . 0 2 9 3}$ \\
\hline Earning Retention & $\mathbf{0 . 0 2 9 0}$ \\
\hline Market Cap/Sales & $\mathbf{0 . 0 8 0 7}$ \\
\hline Price Earning (P/E) & $\mathbf{0 . 1 5 8 3}$ \\
\hline
\end{tabular}

TABLE-2 depicts the weights assigned to each ratio through the AHP method. RONW has been given highest preference due to high variability in it over the past 4 years of functioning of banking firms and Asset turnover ratio has been given least preference due to absence of variability in it over the past 4 years.

The AHP method takes into account the determining the relative merit of a set of alternatives in multi-criteria decision-makers. On the other hand, the PROMETHEE method and the TOPSIS method are arrangement methods. Each method has its own strong points and weak points. The purpose of our research is to find the best choice for the decision takers as well as to access the ranking of companies based on financial performances.

\section{The Analytic Hierarchy Process (AHP)}

The relative preferences of sub-criteria are calculated by taking ratios of coefficient of variance of each company in respect with all other companies. These relative preferences are normalized through the AHP process where we divide the relative preference with the sum of relative preferences. The relative preferences for profitability, valuation, growth and liquidity are calculated by taking average of the sub-criteria's normalized preferences. Process of normalization of these relative preferences is carried out with the help of AHP. After normalization of preferences, we sum it for each company and hence create score of each company for each main criterion. (Given in Table-3, 4, 5, 6)

\begin{tabular}{|l|l|}
\hline PROFITABILITY & SCORE \\
\hline A & 0.1487 \\
\hline B & 0.1105 \\
\hline C & 0.3629 \\
\hline D & 0.2081 \\
\hline E & 0.0412 \\
\hline F & 0.1023 \\
\hline G & 0.0264 \\
\hline
\end{tabular}

TABLE-3 shows the score of each company in profitability criterion calculated by obtaining relative preferences of one company over all other in respective criterion. Here PUNJAB NATIONAL BANK is given highest score.

\begin{tabular}{|l|l|}
\hline LIQUIDITY & SCORE \\
\hline A & 0.1477 \\
\hline B & 0.2226 \\
\hline C & 0.0952 \\
\hline D & 0.0878 \\
\hline E & 0.1413 \\
\hline F & 0.1510 \\
\hline G & 0.1545 \\
\hline
\end{tabular}

TABLE-4 shows the score of each company in liquidity criterion calculated by obtaining relative preferences of one company over all other in respective criterion. Here AXIS BANK is given highest score. 


\begin{tabular}{|l|l|}
\hline GROWTH & SCORE \\
\hline A & 0.1188 \\
\hline B & 0.1291 \\
\hline C & 0.1382 \\
\hline D & 0.1469 \\
\hline E & 0.1198 \\
\hline F & 0.1679 \\
\hline G & 0.1791 \\
\hline
\end{tabular}

TABLE-5 shows the score of each company in growth criterion calculated by obtaining relative preferences of one company over all other in respective criterion. Here ICICI BANK is given highest score.

\begin{tabular}{|l|l|}
\hline VALUATION & SCORE \\
\hline A & 0.0769 \\
\hline B & 0.2895 \\
\hline C & 0.1997 \\
\hline D & 0.1974 \\
\hline E & $\mathbf{0 . 1 1 3 9}$ \\
\hline F & $\mathbf{0 . 0 5 5 2}$ \\
\hline G & $\mathbf{0 . 0 6 7 3}$ \\
\hline
\end{tabular}

TABLE-6 shows the score of each company in valuation criterion calculated by obtaining relative preferences of one company over all other in respective criterion. Here AXIS BANK is given highest score.

The final score for each company is calculated by taking the sum of the product of score of each criterion with the pre-calculated weights. (Given in Table-7)

\begin{tabular}{|l|l|}
\hline & FINAL SCORE \\
\hline PNB & 0.265313 \\
\hline CANARA & $\mathbf{0 . 1 8 2 4 1 1}$ \\
\hline AXIS & 0.171733 \\
\hline SBI & $\mathbf{0 . 1 2 8 9 4 8}$ \\
\hline ICICI & $\mathbf{0 . 1 0 3 6 9 4}$ \\
\hline UNION & $\mathbf{0 . 0 8 0 0 3}$ \\
\hline KOTAK & $\mathbf{0 . 0 6 7 8 7 2}$ \\
\hline
\end{tabular}

TABLE-7 shows the final score for each company. Here PNB BANK is given highest score as it has maximum score in profitability criterion and profitability criterion has maximum weight.

These were the results obtained from the AHP method, we now head to the next technique, TOPSIS.

The Technique of Order Preference by Similarity to Ideal Solution (TOPSIS)

Weighted normalized matrix is created with seven banking firms and four main criteria through the process of TOPSIS.

Positive ideal alternative and negative ideal alternative are calculated which are:

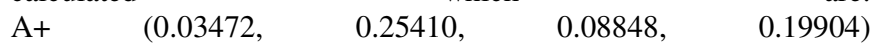
A- $(0.02776,0.10281,0.03598,0.02117)$

\begin{tabular}{|l|l|l|l|}
\hline COMPANY & POSITIVE & NEGATIVE & RELATIVE \\
\hline PNB & 0.2317 & 0.0105 & 0.9566 \\
\hline CANARA & 0.2101 & 0.0494 & 0.8097 \\
\hline AXIS & 0.2039 & 0.0527 & 0.7946 \\
\hline SBI & 0.1578 & 0.1108 & 0.5874 \\
\hline ICICI & 0.1401 & 0.1330 & 0.5129 \\
\hline UNION & 0.1179 & 0.1658 & 0.4156 \\
\hline KOTAK & 0.0772 & 0.1983 & 0.2801 \\
\hline
\end{tabular}

Table-8 depicts the Separation measures which are calculated for each company from both alternatives. After calculating separation measures, we calculate relative measure which is equal to Negative measure divided by sum of positive and negative measure.

These were the results obtained from the TOPSIS method, we now head to the next technique, PROMETHEE.

The PROMETHEE (Preference Ranking Organization Method for Enrichment Evaluation) Method

Our study uses the concept of coefficient of variations to assign weights to the criteria. We have assigned higher weights to criteria having higher coefficient of variation. We have then normalized the weights to cumulate them to 1

\begin{tabular}{|l|l|}
\hline CRITERION & WEIGHT \\
\hline & \\
\hline GROWTH & $\mathbf{0 . 0 4 3 6 9 7}$ \\
\hline LIQUIDITY & $\mathbf{0 . 0 0 8 8 2 1}$ \\
\hline PROFITABILITY & $\mathbf{0 . 8 6 9 5 1 6}$ \\
\hline VALUATION & $\mathbf{0 . 0 7 7 9 6 6}$ \\
\hline & $\mathbf{1}$ \\
\hline
\end{tabular}

Table 9 provides the weights which are used during PROMETHEE analysis. The weights were calculated using the concept of variation, and then normalizing the weights to return the cumulative weight of all criteria to 1 .

PROMETHEE uses the concept of preference ranking on the basis of various criteria. For the sake of uniformity, we use linear preference function for all the four criteria. After analysing data, and providing Preference and Indifference threshold on qualitative basis for all the criteria, we calculate the positive and negative preference of each company for each criteria and reach the final rankings by multiplying the weights of each criteria with the preference (both positive and negative) values of a company.

\begin{tabular}{|l|l|}
\hline \multicolumn{2}{|l|}{$(\mathbf{( + )}$} \\
\hline SBI & 1.921473 \\
\hline AXIS & 1.282613 \\
\hline ICICI & 0.357229 \\
\hline PNB & 1.756673 \\
\hline CANARA & 1.756673 \\
\hline KOTAK & 0.408687 \\
\hline UNION & 0.887158 \\
\hline
\end{tabular}

Table 10 gives the calculation of $\varnothing(+)$ for every company. The value obtained derives how much one company is preferred to another under a specified criterion. 


\begin{tabular}{|l|l|}
\hline SBI & 0.161964 \\
\hline AXIS & 0 \\
\hline ICICI & 2.621779 \\
\hline PNB & 0.391498 \\
\hline CANARA & 0.442956 \\
\hline KOTAK & 4.360811 \\
\hline UNION & 0.391498 \\
\hline
\end{tabular}

Table 11 gives the calculation of $\emptyset(-)$ for every company. The value obtained derives how much other companies are preferred to one company under a specified criterion.

\begin{tabular}{|l|l|l|l|}
\hline & $\varnothing^{\prime}(+)$ & $\varnothing ́(-)$ & $\varnothing$ \\
\hline SBI & 1.921473 & 0.161964 & 1.759509 \\
\hline AXIS & 1.282613 & 0 & 1.282613 \\
\hline ICICI & 0.357229 & 2.621779 & -2.26455 \\
\hline PNB & 1.756673 & 0.391498 & 1.365175 \\
\hline CANARA & 1.756673 & 0.442956 & 1.313717 \\
\hline KOTAK & 0.408687 & 4.360811 & -3.95212 \\
\hline UNION & 0.887158 & 0.391498 & 0.495659 \\
\hline
\end{tabular}

Table 12 give the net $\varnothing$, i.e. Ø(+)-Ø(-). Thus, this value derives which company is more preferred and which is less preferred. As per PROMETHEE, SBI is the most preferred company in terms of financial performance.

After computing the rankings using the three multi-criteria decision analysis techniques, we now do a comparative analysis of the obtained ranks with the actual ranks using Spearman's rank correlation.

\section{Spearman's Rank Correlation}

After analysing and calculating the ranks for the companies from the above methods, we use the concept of Spearman's Correlation Coefficient to study the level of correlation between the actual rankings obtained from the NSE Portal and each of the methods.

\begin{tabular}{|l|l|l|l|}
\hline & PROMETHEE & AHP & TOPSIS \\
\hline SBI & 0 & 9 & 4 \\
\hline PNB & 0 & 1 & 1 \\
\hline CANARA & 1 & 4 & 4 \\
\hline AXIS & 1 & 4 & 1 \\
\hline UNION & 1 & 0 & 0 \\
\hline ICICI & 9 & 4 & 4 \\
\hline KOTAK & 0 & 0 & 0 \\
\hline SUM & 12 & 22 & 14 \\
\hline 6SUM & 72 & 132 & 84 \\
\hline $\begin{array}{l}\text { 6S/(N^3- } \\
\text { N)=Y }\end{array}$ & 0.2142857 & 0.392857 & 0.25 \\
\hline $1-Y$ & 0.7857143 & 0.607143 & 0.75 \\
\hline
\end{tabular}

Table 13 computes the rank correlation coefficient for the three methods, and we can thus conclude that, PROMETHEE is the most correlated to the actual rankings, followed by TOPSIS and then AHP

\section{MANAGERIAL INFERENCE AND CONCLUSION}

In this abstraction, we use the AHP, the PROMETHEE and the TOPSIS methods for the multi-criteria form decision making problem. Also we use hybrid form of the AHP with the TOPSIS and the PROMETHEE thereby, using the benefit from the preferable aspects (strengths) of each model and minimizing the plausible errors.

The objective of the decision making problem and the calculation of the weights allotted to each sub criteria are achieved by the AHP method as the PROMETHEE and the TOPSIS method does not yet provide any suggestion for this division of the MCDM analysis. The PROMETHEE and the TOPSIS method permit the building of an outranking between the different alternatives. As a result, in our abstraction we audit the vitality of the alternatives, how they accomplish our criteria and how they impact on the choice of the function. The hybrids of these methods provide an alternative which is more consequential and accurately fits to the company's interests and targets. Furthermore, it grants us to build a sensible arrangement of companies across four main criteria. The bank firms which are listed on the National Stock Exchange are sorted via the three MCDM models (which are the AHP, the PROMETHEE and the TOPSIS) on the basis of their financial performances. Our study indicates that Punjab National Bank is the best performing bank across the 4 main criteria while Kotak Mahindra Bank is identified as the worst performing bank. Our study also indicates that the ranks given by the three MCDM models have high correlation coefficient.

\begin{tabular}{|l|l|l|l|l|}
\hline FIRMS & AHP & PROMETHEE & TOPSIS & ACTUAL \\
\hline $\begin{array}{l}\text { State Bank of } \\
\text { India }\end{array}$ & 4 & 1 & 3 & 1 \\
\hline Axis Bank & 3 & 4 & 4 & 5 \\
\hline $\begin{array}{l}\text { Punjab National } \\
\text { Bank }\end{array}$ & 1 & 2 & 1 & 2 \\
\hline Canara Bank & 2 & 3 & 2 & 4 \\
\hline ICICI Bank & 5 & 6 & 5 & 3 \\
\hline $\begin{array}{l}\text { Kotak Mahindra } \\
\text { Bank }\end{array}$ & 7 & 7 & 7 & 7 \\
\hline $\begin{array}{l}\text { Union Bank of } \\
\text { India }\end{array}$ & 6 & 5 & 6 & 6 \\
\hline
\end{tabular}

Table 14 gives an overview of the ranks obtained using the three techniques and the actual rankings extracted from NSE portal.

\begin{tabular}{|l|l|}
\hline $\begin{array}{l}\text { Multi-criteria Decision making } \\
\text { Methods }\end{array}$ & $\begin{array}{l}\text { Spearman's coefficient of } \\
\text { correlation }\end{array}$ \\
\hline PROMETHEE & $78.5714 \%$ \\
\hline AHP & $60.7143 \%$ \\
\hline TOPSIS & $75.0000 \%$ \\
\hline
\end{tabular}

Table 15 gives an overview of the Spearman's rank correlation, indicating that for the given study, PROMETHEE gives the most correlated results with the actual scenario, followed by TOPSIS and AHP.

\section{Limitations AND FURTHER SCOPE OF STUDY}

The research is conducted on the banking-sector industry. Thus, there is further scope of using the techniques to evaluate decisions within other industries, as well as across industries.

Also, the given study makes the use of four main criteria with nine sub-criteria. The criteria and the techniques to evaluate the criteria can be further explored. 


\section{REFERENCES}

[1] Halim Kazan, Merve Ertok, Cihan Ciftci (2015) Application of a Hybrid Method in the Financial Analysis of Firm Performance, World Conference on Technology, Innovation and Entrepreneurship

[2] Velasquez M and Hester P T 2013 An Analysis of Multi-Criteria Decision Making Methods, International Journal of Operations Research 10(2)56-66

[3] F. C.-G. Pablo Aragonés-Beltrán, Juan-Pascual Pastor-Ferrando and Andrea Pla-Rubio, "An AHP (Analytic Hierarchy Process)/ANP (Analytic Network Process)-based multi-criteria decision approach for the selection of solar-thermal power plant investment projects," Energy, vol. 66, pp. 222-238, 2014.

[4] N. M. a. M. J. H. Jahromib, "Propose a model to choose best project by AHP in distributed generation," Procedia Technology, vol. 1, pp. 481-484, 2012

[5] T. a. T. A. Nooshin Rahmania, "Developing a Multi Criteria Model for Stochastic IT Portfolio Selection by AHP Method," Procedia Social and Behavioral Sciences, vol. 62, pp. 1041 - 1045, 2012
[6] B. Oztaysi, "A decision model for information technology selection using AHP integrated TOPSIS-Grey: The case of content management systems," Knowledge-Based Systems, 2014.

[7] Albadvi., A., Chaharsooghi, S.K., \& Esfahanipour, A. (2007). Decision making in stock trading: an application of PROMETHEE. European Journal of Operational Research, 177, 673-683

[8] Bhushan, N., Rai, K. (2004). Strategic decision making applying the Analytic Hierarchy Process. The United States of America: Springer.

[9] Bilsel, R. U., Büyüközkan, G., Ruan, D. (2006). A fuzzy prefernce-ranking model for a quality evaluation of hospital web sites. International Journal of Intelligent Systems, 21, 1181-1197.

[10] http://www.managementstudyguide.com/decision-making.htm

[11] https://en.wikipedia.org/wiki/Multiple-criteria_decision_analysis

[12] https://en.wikipedia.org/wiki/Spearman $\% 27 \mathrm{~s}$ rank correlation coefficient

[13] Multiple criteria decision analysis- state of the art surveys- edited by FIGUEIRA, EHRGOTT AND GRECO 